\title{
Objective and Subjective Factors in Economy and Economics
}

\author{
Yuriy Knyazev \\ Centre for East European Studies, Russian Academy of Sciences Institute of Economy, Moscow, Russia
}

\section{Email address:}

kyuk151@rambler.ru

\section{To cite this article:}

Yuriy Knyazev. Objective and Subjective Factors in Economy and Economics. Journal of World Economic Research. Vol. 10, No. 1, 2021, pp. 1-9. doi: 10.11648/j.jwer.20211001.11

Received: December 21, 2020; Accepted: January 6, 2021; Published: January 25, 2021

\begin{abstract}
The paper is aimed to substantiate that in modern economy, besides the market, a public sphere exists and develops according to its inherent non-market logic. This issue is regarded from the point of view of correlation between objective and subjective factors in the economy. The author expounds his conception of these factors' correlation, the evolution of scientific insights in their role in society, explains the specificity of subjective forces' functioning judging from the positions of methodological dualism, which combines the principles of individualism and collectivism. The dual nature of human personality combining contradictory fundamentals of instinctive individualism and collectivism acquired in society explains people's substantial behavioral differences under market conditions and in the public sphere. In the paper the differing importance of objective and subjective factors in the market and non-market spheres of economy is substantiated: the market area is managed mainly by objective regularities, which reduce people's subjective actions to a common denominator, whereas in the public sphere, on the contrary, the leading role is played by subjective notions of public interests, of benefit and mischief resulting from any intentions, of further development goals and ways. In the final part of the research the author presents his characteristic of the public sphere, which functions besides the market but with the latter demands in view, and therefore requires an in-depth study of its inherent regularities, including the state fulfilling its regulating role in market economy.
\end{abstract}

Keywords: Objective and Subjective Factors, Market and Non-market Spheres, Individualism and Collectivism, Methodological Dualism, The Public Sphere and Its Regularities, The Role of the State in Market Economy

\section{Introduction}

In economic theory, like in other social sciences, main attention is concentrated on researching objective things, events, processes, i.e. those non-dependent on people's will. This can be explained by researchers' intention to apply in public life the reality cognition methodology practiced by natural sciences. However, in nature everything is predestinated irrespective of people's behavior, because people are bound to square their activity with natural laws and can only apply some of them to meet their own needs. In society, on the contrary, objective regularities as such evolve due to independent actions of multiple individuals who, on the one hand, participate in creating and changing behavioral stereotypes and development trends, common to all of them, and, on the other hand, are bound to take these into account in their everyday life in order not to get outplayed.

It is this singularity of objective laws in effect in society, that predetermines particular importance of studying the subjective activity of people not only in their entire mass, but also that of groups, layers, classes and also individuals - each taken separately - and reveal their common features typical for the so-called representative sample. This was the starting point for the classics of economic science when they revealed targeted intentions inherent to any person engaged in economic activity. According to the classics, the individual striving of homo oeconomicus for material welfare as principal driving motive, is, in their view, inherent to any rational actor. Thus, the well-known principle of methodological individualism has been established. It was sufficient enough to explain processes of goods exchange under way on the market and also in the production sphere consisting of self-sustaining private owners.

But in the course of historic development, it became progressively obvious that this approach suffers from being one-sided: it does not take into account the dualism of nature 
of the human being, with his two contrary fundamentals innate instinctive individualism and collectivism acquired due to finding himself in society among those of his kind. Without the collective spirit human society could not simply have existed. If the description of the market could, in general, get along without counting on the collective guise of human personality, people's life beyond the market (in family, when establishing interpersonal relations, in state-run entities, civil society agencies, in international relations) is regulated differently - proceeding not only from inalienable individualism, but also in tune with collectivistic requirements, meaning the wish and ability to live in society.

Recognition of the human being's dual nature, in our view, gives rise to indispensably dividing the activity area into two spheres - the market one and the public one. In the market one mainly individualistic features of human personality come to be seen, although collective proclivities also take place, but they play a subordinate role. In the public sphere interpreted extensively (and not only in form of support of citizens in need), people, on the contrary, expose a collectivistic fundamental. But individualistic incentives do not disappear, they are inhibited by state power agencies in case they become dangerous for society.

People's behavior in both spheres is exclusively subjective because people are guided by their emotions, by reason and will. But the behavior is still different due to specificity of these spheres. On the market the individuals are obliged to somehow coordinate their actions with the requirements of objective market laws; in the public sphere, however, they act absolutely free in the sense that they can take into consideration the regularities known to them or disregard them. But, instead, they are obliged to comply with community life rules established by society subjectively as well. In consequence, broader subjectivism reigns in the public sphere compared with the market one. However, if the requirements of objective laws are not taken here into consideration unknowingly or intentionally, then individual personalities and society at large will be able to feel their negative consequences not at once, but in longer term.

In this paper an attempt is made to bring to light the place of objective and subjective factors in economy on a premise that human personality's dual nature and the specificity of the two spheres of his life-sustaining activity - the market one and the public one - are acknowledged.

\section{The Evolution of Views on the Problem}

\section{1. "The Objective» and "The Subjective» in the Life of Society}

In the scientific discourse different approaches to economic theory comprehension are clashing, they often oppose each other and claim exclusive genuineness, thus creating the impression that consensus cannot be achieved and that the striving towards a general theoretical conception of economy common for all is, consequently, useless. In reality, however, economic science (like any other science) cannot be but unified, homogeneous because it implies, actually, the comprehension of one and the same object - the economy, whereas various theoretical trends and schools only explain, in a different way and within their aspects, its essence and specific manifestations. Very significant is here the fact that emphasis is often paid either on objective or on subjective factors. Therefore, theoretical constructions differ radically and often even come on incompatible. Clarifying the given issue allows to look at the conjunction of existing economic theories from a different perspective and understand the importance of every one of them in the development of the general science of economy.

There is a substantial difference in understanding "the objective" in nature and in human society. In inanimate nature, in the vegetable and animal worlds, all processes are objective, they run by themselves, irrespective of concrete situations individual participants (nonliving objects, plants or animals acting on instinct, i.e., unconsciously) find themselves in. In contrast, people always act subjectively, in according to their wishes, at the same time without understanding that their actions, in a form veiled to them, are limited by a certain objective framework beyond their control. This framework is imposed by macro-processes going on irrespective of individual people, and these macroprocesses represent the resulting trends of often contradictory actions - if regarded by each of them separately - with a differing impact on the general outcome. In the final count, they are unable to resist the general development course of human society defined irrespective of separate people, i.e., objectively. These objective tendencies constitute these indefeasible laws and not quite long-present development regularities of societal development (its economy included), which are objects of social sciences studies (economic theory included).

In addition, the role played by the subjective factor in objective processes should not be underestimated. Apart from the fact that in economy objective laws are the resultant of volitional operations of all actors, who, in the end, in one way or another, influence their formation. Important is also the role of individual persons, primarily those exercising power. Distinguished personalities or self-sustained social groups can affect the public development process (accelerate or decelerate it) and even, under certain conditions, reverse it temporarily. This happened, for example, in early 20thcentury Russia when the Bolsheviks headed by V.I.Lenin launched "the historic flash forward" - an endeavor to build socialism in a separate country without the objective conditions being ripe for it. Goals set by people can be imposed on them and even become destructive for them [2].

\subsection{The Position of the Classical Theory and of Neo-classicists}

Historically, interest in objective and subjective sides of people's life-sustaining activities manifested itself, with differing intensity, in various epochs - depending on top priority goals the humanity - embodied in its progressive 
vanguard - was facing. With economic theory in inception in Britain in the period of fostering capitalist regime, it was important to unmask the role of objective processes (which did not dependent of separate persons' will) by opposing them to subjective actions of sovereign kings, feudal lords and state bodies. That is why the classical economic theory was predominantly engaged in researching objective market laws managed by the "invisible hand" [18], i.e., acting arbitrarily, irrespective of individual goods producers' and goods consumers' will, that is, as the resultant of fragmented efforts of multiple market actors.

It was precisely in those times when objective market economy laws were discovered: the law of value and resulting pricing regularities, the laws of demand-and-supply market interaction, relevant goods producers' behavior, capital allocation and cumulative reproduction process functioning as a unity of production, exchange, distribution and consumption spheres.

Already the Neo-classicists, who disagreed with labor theory of value - which, as is known, held the exchange (market) value for a constantly changing abstract value that could not be measured and differs in this respect from Dame Quickly, that we don't know "where to have it" according to K.Marx [10] - paid special attention to the study of concrete goods buyers' and sellers', consumers' and producers' market behavior, i.e. to subjective actions of people. They, in their aggregate, from the start mold market regularities and simultaneously also adapt themselves individually to them by taking them into account or by violating them unconsciously or consciously in the hope of their personal good fortune (entrepreneurial risk). The fundament of Neoclassicists' marginal approach is the notion of use value, which is always concrete but difficult to be compared in the exchange process of heterogeneous commodities. It turned out to be possible to approximately foretell, purely mathematically, the price dynamics of any commodity by exposing its "marginal utility" expressed in the price the buyer is ready to pay for the last commodity sold under current demand-and-supply relationship (beyond this margin, the commodity ceases to be useful for the consumer and, therefore, should not be produced).

The market value of a commodity - as characterized in the 3rd volume of "Capital" - is a permanently changing abstract quantity resulting from demand-and-supply interplay. In this process the authentic value of the commodity for given solvent demand comes to be revealed, that is, the amount of socially-necessary labor representing the substance of value. Herewith, the socially-necessary amount of real labor input can be not only lower than its actual amount (in case the superfluous part of labor is spent ineffectively and is not taken into account by the market), but is much bigger than real labor input, in case the commodity is in higher demand thanks to being rare or more attractive for the buyer. This means that it contains a much bigger amount of sociallynecessary labor compared to that really put in to produce the given commodity.

In essence, the Neo-classicists do not negate the existence of objective market laws, however, they embarked on the way of studying the mechanism of their formation more carefully and in cooperation with subjective participants of market relations. The latter are guided by their own interests and make use of their intellectual, intuitive, volitive capabilities to attain production and commercial aims. In addition, market actors, on the one hand, have to take into account the existing conditions and economic management rules set by widely accepted practice, which has taken shape under the impact of objective laws. On the other hand, in the course of competition they have to commit on infracting these rules and changing the acting short-time criteria of efficiency - hoping to gain a long-term advantage thanks to sound entrepreneurial risk. Thus, market actors, unaware of requirements introduced by market regularities and only intuitively suspecting their existence, behave exclusively at their own will; in this way they participate in these regularities' formation and, simultaneously, in adapting to these their activity.

The insight into this mechanism of objective and subjective factors interaction has allowed the Neo-classicists not only to make use of marginalistic research methods, but also to develop behavior models for practicing entrepreneurs and financial industry experts engaged on commodity and stock markets, in securities dealing in particular. Since these models became widely needed in practice, economists gained the chance at last to make profit in applying theoretical knowledge in practice by providing well-paid consulting services.

Consequently, the Neo-classicists, by contrast with economic theory founders, started to investigate objective regularities in combination with the study and explanation of market participants' subjective motives. Thus, they realized their importance in science and economic practice. But they limited themselves with studying the subjective factors only in the sphere of purely market relations, on the level of free market actors, and did not go further, thus disregarding other public actors having real impact on economic development, including regulation of market itself. This was not needed in times when the regulating impact on public entities, primarily the state, has not yet been broad and not yet visible for scientific analysts.

\subsection{Modern Age Modification of Views}

The situation in economic science started to change with the increasing role of the state and civil society entities. This lead to investigate precisely these subjective factors, find out their role and importance in economic development on microlevel and on macroeconomic scale. Besides, the contribution made by the Classicists and Neo-classicists in discovering and describing fundamental market economy laws was so weighty that, for a lengthy time, it distracted researchers from further creative studies of the issue, which has turned into a dogma within the unchangeable mainstream of economic science. But the needs of practical life compelled to find other approaches to explain modern realities of economic activity. And the majority of new trends 
in theoretical thought has centered precisely on investigating subjective factors in the economy.

This topic is being studied along two main lines. Some scientific schools tending to the liberal discourse concentrate on evidentiating individuals' cognitive and psychological singularities, which influence their behavior on the market as consumers, buyers and sellers, businessmen and financial experts. Other schools, which fall into the category of dirigists (regularists) pay special attention to public aspects of people's life-sustaining activity and to the functioning of state entities and civil society organizations.

The first trend may include scientific schools engaged in studies of regularities of individual and collective choice as well as differences in cognitive peculiarities and psychological qualities of people, who influence substantially their behavior as economic agents (including business strategy choice made by various businessmen).

The need to individualize the generalized economic agent emerged because during a lengthy period of time this agent has been simplistically qualified by theoreticians as exceedingly undifferentiated and hermetic for researchers; the latter saw no need to go into the peculiarities of every single personality inasmuch as all people allegedly act uniformly in similar situations and change their behavior only under the impact of changed objective conditions. "Individuals set equal to black boxes that somehow on end show their preferences by choosing some goods out of their multiplicity. The models of choice supposed that the individual maximizes his utility function within the framework of budget constraints (probably effective demand is meant here - Yu.K.), and that the set of goods ensuring it will be chosen and consumed. These black boxes were vested with the rationality quality, i.e., full knowledge of goods and one's needs, non-limited computational capabilities and, thus, the chance to make the optimal choice. The utility function was not, actually, an expression of knowledge mentioned: the inner world of individuals as economic agents, their subjective insight into the outer environment, knowledge of themselves and other individuals, etc., remained beyond the economic analysis" [20, p. 9].

It stands to reason that to understand the mechanisms of objective laws functioning the notions of "representative agent" [7, 9] and "representative company" [13, 17] were sufficient because the market raised the same demands to all individual agents and companies, and all of them were forced to react in the same way in order not to come off losers in competition. Strict dependence of pricing on demand-andsupply balance of a commodity or service brings market actors' individual intentions and internal singularities to a common standard. The main thing is competitive pricequality relationship of their products. But this counterbalancing approach does not really disclose the formation mechanism of market regularities themselves, which depends on market actors' individual specificities. Above all, it does not explain the latter's genuine motivations, whose knowledge need marketing experts to evaluate massive preferences, advertisers to work with separate groups of buyers, brokers to take into account exchange deals risks, consulting agencies to serve the customers. All this is important not only for in-depth theoretical research, but also for practical work of economists and financial experts engaged in management on microeconomics level.

Relatively long ago certain scientific workers began to show interest in topics of this kind. We have to mention the works by F.Hayek, representatives of the Austrian School of Economics, who made "a turn to knowledge"; G.Simon who came up with his concept of bounded rationality of economic agents without unlimited computational capabilities; A.Tversky and D.Kahneman who investigated the impact of psychological deviances and euristic capabilities on economic behavior [21]; O.Williamson, who analyzed the phenomenon of opportunism in economic agents' behavior [22]; F. Denzau and D.North, who exposed the influence on behavior not only of formal but informal rules as well, as also of different mental models [6]. The above papers underpinned the strands like behavioral economics and new institutional economic theory [20], also neuroeconomics [4, 7], "mentalism" and "behaviorism", "informational paradigm" [19], "information asymmetry" [1] and other branches of theoretical thought engaged in studying the consequences for various markets of phenomena like fashion, crazes, gregarious behavior and other people's peculiar actions depending on their individual and collective qualities, i.e. on subjective factors.

Whereas in microeconomics the scientific interest in the subjective side of people's and companies' activities has been on full display and in a multitude of trends, on the macrolevel this process is going on more slowly, up to now it is faintly identified in form of special scientific schools. After all, precisely in macroeconomics any life-sustaining activity is subjectively tinged in the sense that decisions are taken arbitrarily by concrete entities (primarily by the state and also by civil society organizations). That is, they are not an automatic manifestation of some objectively developing processes. This does not mean that these decisions do not depend on certain regularities, known or unknown to regulating actors; however, the latter adopt them independently and bear full responsibility for their completion.

The mainstream of economic theory pays principal attention to the market sphere, and, within it, to the activity of self-sustaining and scattered actors and to regularities of their behavior on the market. However, it is, of course, impossible to avoid citing and cursory characterizing public entities constantly present both in the market sphere and, in particular, in the public sphere in form of all sorts of state-run agencies and civil society organizations, which are gaining momentum. But these entities are perceived as side elements of self-reliant market, they rather disturb natural competitive relations. For the sake of pure theory, these may be disregarded. Nevertheless, it is impossible to evade this issue. Honest researchers have to acknowledge that the regulating role of public entities is of no small matter in the economy 
and the public sphere.

In the textbook by P.Samuelson (published in Russian translation in 1992 under the title "Economics" and wellknown to Russian readers), in the author's own words, the principal methods of analyzing mayor facts and institutions of modern economic life are exposed, the concept of national income, saving and investing interaction, which determines the purchasing power level, of population's incomes and employment level, «competition and monopoly forces, which, by way of supply-and-demand mechanism, participate in designing the structure of national income expressed in commodities and services produced and also in their prices, as well as the mechanism of income distribution in form of wages, rent income, percent rate and profit» [16].

In this two-volume textbook consisting of forty-one chapters two of them deal all about the economic role of the state, federal taxes, local finances and budgetary expenditures. The author mentions also the role of governmental monetary and fiscal policy in stabilizing business activity "on a sound level of progressive growth", the need for tariff protection and support of the country's balance of payments. Without going, at the moment, into assessing the validity of so limited understanding of the role of the state in regulating economic life, let us underline that this regulation presents already not separate persons' subjective activity, but that of competent authorities' public interests.

Institutionalism as contraposition to orthodox theory has become a fleshed-out scientific trend wholly dedicated to the study of subjective factors in human society, the economic sphere included. R.Coase [4], M.North and other [12], founders of institutionalism, paid attention to the key role of habits, traditions, convictions common to a multitude of people (nations, ethnic groups, social strata). They called them institutions regulating human relations in everyday life and other areas of life-activity. Along with these spontaneous, non-formal rules of behavior, legal norms, made regular by conformance to law and protected by the state, exist in any society. These norms are also institutions formally established by state entities and are binding. Thus, institutions constitute the rules and norms, which people consciously comply with, and, what is most important, which are the product of subjective creativity of people themselves and of entities they represent.

According to Institutionalists, the mighty impact institutions exert on economic life finds its expression in growing transaction costs, which, in the modern world, in terms of volume, even exceed transformational costs the companies bear in the process of immediate production. A specific normative regulation environment people have created with state participation in order to protect property and general conditions of property disposition (numerous legal services and a network of financial mediators included) has become an inalienable and so important component of business activity, that the idea emerged to regard this sphere not only from the point of view of inevitable transaction costs, but also as development potential, as increase in non- production assets - by analogy to investments, inventiveness, patenting and other innovations.

The Neo-institutionalists have insomuch promoted the root ideas of their scientific school that started to apply the notion of institutions not only to norms and rules, but also to any entities and organizations, even to some aspects of their activity (e.g., they mention the institution of planning, industrial policy, etc.). This produces the impression that it is suggested to call an institution everything thought of and materialized in reality by human society in terms of social arrangement of people's livelihood.

Thus, within the entire spectrum of scientific researches, institutionalism occupies the niche diametrically opposed to that of economic theory classics, it concentrates chiefly on its subjective aspects and ignores, in essence, any objective background. But the aim of science consists not only in describing events and facts and their classification from a definite perspective, but also in bringing to light objective regularities of their existence and development. Until this becomes the kernel of institutional school, it will be, as before, taken as "theory without a theory" as it has been customary since its very inception.

For our research, institutionalism is of importance as academic trend that paid attention to the subjective side of economic life, moreover, not so much to individual actors of market and other relations, but to multiple and various public entities, which often play a crucial role in the life of any socium.

\section{Enhanced Academic Interest in the Public Sphere}

Unfortunately, widely recognized academic schools that might declare themselves as researchers not only of the market sphere, but also of the coexisting public sphere (the latter develops according to its own laws but together with inevitable market one, thus making a comprehensive whole) have not yet taken shape. With this insight, modern economy appears as a synthesis of market and public regulation [8].

Nevertheless, in economic literature a growing number of publications appear dedicated to new approaches to conceive processes going on precisely in the public sphere, which, in modern economy, plays no lesser role than market relations researched thoroughly and long ago in their theoretical and practical dimensions. This set of issues is regarded not only in line with the solution of current tasks linked with overcoming stepped-up critical situations and with propping up the falling economic growth, but also in forecasting future development of individual countries and humanity as a whole.

The early pioneers of the public trend in economic thought were German Ordoliberals who developed the social market economy theory (Soziale Marktwirtschaft). It tried to divert from the classical interpretation of economy as exclusively sweeping and self-sustaining market. In their view, market itself is unable to successfully solve all economic problems, 
it becomes more efficient in case society advances goals of social quality. In post-war Germany these ideas were partially realized in the policy of LErhard and K.Adenauer.

Since then, interest in treating topics in market economy connected with the role of public factors - the state in the first place - does not only not wane, but is constantly growing. The most available theory of this kind is the conception of economic sociodynamics (CES) [3]. The operative motive for its creation became the growing role of public factors in modern economy that should be taken into consideration in theory as well. The authors of this conception hold that society has its own interests, which cannot be reduced to preferences of individuals. The state as independent market actor is spokesman of public interests. The theory of patronized (by the state) goods [14, 15] rests upon the fundament of Masgrave's theory of merit goods [11] and presents an extension of CES. An important CES component is the enunciation of complementarity of methodological individualism, i.e., recognition of complementarity of individual preferences and public interests.

Extending the public issue in economic theory, the author of the paper suggests his own treatment of its several important premises. A typical feature of this approach consists in singling out the public sphere of economy as an independent research object on the ground that it develops according to its own laws, but in tight interaction with the unavoidable market. The principal difference of this trend from many other consists in the fact that it does not strive to dispose of orthodox general-theoretical statements by counterposing their different perception within the framework of the same generally known market paradigm. He suggests to slightly digress from this paradigm when regarding the specificity of the public sphere.

It is obvious for every impartial observer that economy is not confined to market relations. Apart from the market, a broad sphere exists in society, which is functioning according to its own, non-market logic. In this public sphere the same actors (physical persons and organizations) operate, they are market actors, but behave not only the way prescribed by methodological individualism, they are guided also by public interests. This is primarily explained by the fact that two contradictory fundamentals are present in a person as a public creature: instinctive animal individualism and acquired collectivism, i.e., the desire and capability to live in society of his like. The actions of social sphere actors, as a rule, do not conform to any limitations of public type, they are limited only by existing natural and other physical conditions they are unable to change. They can exclusively voluntarily take into consideration objective public development laws, if they know them. But disregarding them inevitably leads to serious losses for society.

The public sphere actors are motivated not only by their individual material and spiritual needs, but also by teams interests and those of society at large, which secure their survival and development. The public sphere is pierced through by collectivity relations, which spontaneously emerge among people and are also established by organizations, which society members create to protect common interests and carry out concerted undertakings.

The generally accepted moral rules (religious and secular commandments) promote the creation of a public habitat acceptable to all. Moral rules are furnished out by severe community norms, whose observation is secured by laws and other normative acts, which provide sanctions in case of their infringement. Historically, it was the state embodied by government agencies (which bring about normal lifesustaining activity of the entire society and its individual members) that started to carry out the functions of introducing these norms and their enforcement.

This need appears due to the fact that people are rather heterogenous and differ in their physical force, mental capabilities and well-being. To avoid that those endowed with these qualities more than others dominate over the rest, all people had to be made equal, first and foremost, legally. Freedom - natural for primitive people - had to be limited with the help of community life norms by ensuring equality of all before the law. But this turned out to be insufficient for society's harmonic development without excesses inevitably surging among people because of different levels of provision with means of subsistence. These differences had to be smoothed out by ensuring material support for those in need and, in this way, partially conferring the quality of consanguineous ties to human relations. The well-known triplicity of "freedom, equality, fraternity" has precisely this integrating meaning.

The absolute majority of people voluntarily abide community life rules thanks to their education in family, at school and other public organizations. Those who ignore the rules have to do with law-enforcement agencies, which punish for misconduct and crimes.

The public sphere, being in principle other than the market one, is meant to practically maintain this public order. Individualism reigns mainly on the market, whereas the public sphere is predominantly regulated by collective spirit. Consequently, when studying real life of society, it is necessary to proceed from methodological dualism, i.e., the inevitable junction of individualism and collectivism.

\section{The Characteristic of the Public Sphere and the Role of the State}

\subsection{Main Features of the Public Sphere}

Institutionally, the public sphere comprises entities of government administration, defense, law and order, welfare protection, public health services, education, science, culture. These structures are practically engaged in securing a safe and full-on life of citizens and the whole society. Although the public sphere functions chiefly not according to market laws, market criteria are also applied here, but mainly to optimize society's expenses needed to reach the goals set by regulating bodies at their own choosing, in a best-case scenario with citizens' participation and with regard to the entire conjunction of scientific knowledge. 
The specificity of the public sphere consists also in the fact that it is structured according to the subordination principle, which implies the existence of the leading center with its regulating function aimed primarily at maintaining reasonable existence conditions in society of all its members. This function is realized with differing efficiency level, but has to reach the main goal: to ensure survivance of the socium and eliminate threats of its disruption by destructive forces not willing to comply with established community life rules.

The general characteristic of the public sphere in its broad meaning - as a special area of public regulation - refers also to economy, where it is notable for its specificities. Economic regulation is carried out primarily by governmental impact on market relations in order to exclude or anticipate "market failures" leading to serious material losses, which particularly result from periodical overproduction crises or financial cataclysms. This refers not only to harmonizing interpersonal relations but also to straightening out constantly emerging economic and social problems. These cannot be resolved by the market itself, because it produces these problems constantly due to short-term efficiency criteria in force on the market. Issues relating to changes in the sectoral structure of economy and economic growth acceleration can find a solution only in the long run and often contrary to momentary market logic. This work can be done arbitrarily by the state only, by applying accumulated world experience and scientific knowledge of macroeconomic development.

\subsection{The Enhancing Role of the State}

The liberal perception of the state as "night watchman" minimally interfering in economic life is inconsistent with the perception of the public sphere as an independent area (along with the market) of people's life-sustaining activity; to study the public sphere it is necessary to be guided by methodological collectivism, because methodological individualism does not suit here since it disagrees with existentialist needs of society as such. Society consisting of individuals (like a forest consisting of separate trees) is able to exist only on condition it preserves the commonness of its integrating elements bound to correspond to their environment and develop under its impact. For human society this environment is created under the impact of community spirit, which provides for its survival. The collective spirit is produced not on the market, but only in the public sphere, by constantly struggling against every person's inborn individualism, particularly against those in whom this human primordium prevails and makes them selfish.

The economic functions of the state emerged simultaneously with those securing internal law and order and external defense capacity; to attain these it was necessary to collect taxes and set up a corresponding infrastructure. With state functions expanding, the array of tools for their economic provision was becoming broader. But the function of regulating economy itself evolved gradually as a separate area of society's self-sustaining activity. First of all, the need appeared to amend unfavorable market processes leading to various problems, which appeared in the public sphere and gave rise to critical situations in production and financial area. Then the state got engaged with issues connected with the general process of economic development - a process the market itself is unable to change rapidly due to inertness of processes on the market. This necessity appears if sectoral and technology structures become archaic, if the scientifictechnical potential lags in its development and economic growth decelerates. Government intervention in these problems becomes particularly topical in globalization era, when many countries and their native businesses cannot compete on equal terms with leading countries and big transnational corporations on international and even domestic markets because of excessive openness of the latter.

The state activity area is mainly macroeconomy with its objective laws of functioning, which differ from market regularities of microeconomy, where self-sustaining enterprises (companies and their different alliances) are functioning. The state has an entire arsenal of means and methods at its disposal to impact on economic processes. The most widespread ones are monetary and fiscal policy, which produces an adjusting and governing effect on economy as a whole and on its separate sectors, microlevel included.

An ever-greater role plays the state budget in exerting a regulating impact on the current trend of economic development in form of both budgetary means distribution and formation on the basis of taxes and levies. Almost all states, in no lesser degree than private business, are funding the science and research sector. Moreover, they create favorable economic conditions to introduce research and development applications into production with tax allowances and price subsidies made available. Only in this way have the United States managed to introduce the so called "shale revolution" and secured, on the account of budgetary means, the competitiveness of more productioncostly oil and natural gas extracted in shales. Northern Sea basin countries and the European Union act exactly in the same way by intentionally pursuing the policy of transition to renewable energy resources, their production by wind turbines and solar power plants is heavily subsidized by the state budget. Practically all countries are compelled to subsidize agriculture not because of high agricultural production costs and those of surface infrastructure development of the countryside, but also to support competitive national production as compared to foreign counterparts.

Globalization made many countries turn to perfecting the sectoral and production structure of their economies. Traditional sectors lose their competitiveness owing to the fact that new types of high-tech products appear. Obsolete productions have to be closed, more modern ones have to be developed, which is impossible without governmental support. It is thanks to targeted governmental programs that the so called "Asian tigers" (a series of South-East Asian countries) managed, in a short time, to start producing automobiles and domestic electronic equipment and ensured their large-scale export. 
The state is compelled to get more and more engaged in problems connected with supporting and accelerating economic growth. This is required not only because of the need of new job creation and advance of population's living standard, but also because of growing international competition, which makes it necessary for countries to participate in the general race for survival and for "the best place under the sun". Business itself, even the very big one, is unable to successfully respond to new challenges, it needs governmental support.

The development of modern economy requires not only current regulation, but also long-time planning when implementing socio-economic strategies. For a very long time already several big countries have been practicing indicative planning which sets nationwide goals, whose attainment is ensured mainly by indirect means from the arsenal of monetary, tax, budgetary and credit policy. This planning is sufficient in countries, which successfully develop in an evolutionary way, that is they are in no need of radical and quick transformations. This kind of planning is obviously insufficient for countries, which, as Russia, face tasks linked with changing the sectoral structure of economy, with innovative renewal of its production potential, with economic growth acceleration, and solution of multiple social problems. These countries are in need of complex planning that embraces nation's economy and takes into account the entire variety of links existing between their principal components and their probable changes. Planning should be not of optional, but of binding character in the sense that fulfillment of tasks set should be made sure in due time. In contrast to soviet directive planning, it can be based on voluntary participation of business in realizing big nationlevel projects by applying the form of public-private partnership, which provides for joint shared financing, preferential taxation and crediting, new products distribution on the home market guaranteed by the state, and mostfavored nation treatment for export.

If in the public sphere all participants behave exclusively at their own choosing, i.e., absolutely subjectively, it is necessary, in conclusion, to answer the question whether objective regularities work there. In the market sphere these laws exist, they make for the underlying trends that reflect general tendencies in multidirectional efforts undertaken by a multitude of actors. It is predictable to assume that similar regularities function in the public sphere as well. As far as relations between individual people are concerned, who combine, to a different extent, individualistic and collectivistic strivings, the general trends in society represent also the resulting impact of certain equally effective forces that reflect the prevailing role of these or other layers or long-established population groups. However, the overwhelming trends are, nevertheless, collectivistic ones. Otherwise, society could not have existed and developed, because it would have simply disintegrated under the impact of mass egoistic strivings.

A rational and responsible state power should be guided by public development laws it is aware of, including those related to macroeconomy, when regulation of the economic sphere is in view. This raises a vital demand to economic science not to confine itself to the study of market relations, but also pay the same careful attention to processes going on in the public sphere. In this field theoretical discoveries are still to be made. Discoveries, undoubtedly helpful for state regulation practice of economy in any country, in Russia in particular, since it experiences a pressing need for economic growth acceleration, production structure modernization and pending social problems solution.

\section{Conclusion}

In economic science an unproportionally important place is granted to the problem of market in prejudice of nonmarket relations, which, nevertheless, remain deciding in the development of human society. In country economies the role of state regulation is increasing, it sets the main development goals, to attain them it mobilizes budgetary financial resources exceeding in some cases $50 \%$ of GDP volume. All this makes us cast a different look at the role of public factors in society, economy included, which in our time does not reduce itself to market relations only, but also involves its immanent non-market, public sphere.

This problem is examined in the paper from the perspective of correlation between objective and subjective factors in the economy. The market sphere is regulated mainly by objective laws. which align people's subjective actions. In the public sphere, by contrast, the decisive role is played by subjective notions linked with public interests, beneficial or harmful intentions, aims and ways of future development.

The author's characteristic of the public sphere is presented, the role of the state in market economy is specified, the principle of methodological dualism (combination of individualism and collectivism) in economic theory is upheld. Clarifying these points allows to move to a new level of theoretical generalizations and may give a fresh impetus for practical transformations in many countries.

\section{References}

[1] Akerlof O. A. (1970). The market for 'lemons'. Quality uncertainty and the market mechanism. Quarterly Journal of Economics, Vol. 84, No. 3, pp. 488-500. https://doi.org/10.2307/1879431

[2] Arrighi G. (2006). Long twentieth century: Money, power and sources of our time. Moscow: Territory of the Future Publishing House. 472 p. (in Russian)

[3] Grinberg R. S., Rubinshtein A. Ya. (2000). Economic sociodynamics. Moscow: IEPress. (in Russian)

[4] Camerer C., Loewenstein G., Prelec D. (2005). Neuroeconomics. How neuroscience can inform economics. Journal of Economic Literature, Vol. 43, No. 1, pp. 9-64. https://doi.org/10.1257/0022051053737843 
[5] Coase R. H. (1937) The nature of the firm. Economica, New Series, Vol. 4, No. 16, pp. 386-405/ https://doi.org/10.1111/j.1468.0335.1937.tb00002.x.

[6] Denzau A., North D. (1994) Shared mental models, ideologies and institutions, Kyklos, Vol. 47, No. 1, pp. 3-31. /http://doi.org/10.1111/j1467-6435.1994.tb02246.x.

[7] Hartley J. E. (1996) The origin of the representative agent. Journal of Economic Perspectives, Vol. 10, No. 2, pp. 1 69177. https://doi.org/10.1257/jep.10.2.169

[8] Knyazev Yu. K. (2014). Contemporary economy - synthesis of market and public regulation. Moscow: Infra-M. (in Russian)

[9] Koppl R. (2011). Against representative agent methodology. Review of Austrian Economics. Vol 24, No. 1, pp. 43-55. https://doi.org/10.1997/s11138-o1o-0119z.

[10] Marx K. (1969). The Capital. Parts 1-3/Marx K., Engels F. Works. 2-d edition. Vol 23-25. Moscow: Politizdat. (in Russian)

[11] Masgrave R., Masgrave P. (2009). State finances: theory and practice. Moscow, Business Atlas (in Russian)

[12] North M., Macal C. (2007). Managing business complexity: Discovering strategic solutions with agent-based modeling and simulation. Oxford University Press.

[13] Robbins L. (1928). The representative firm. Economic Journal. Vol. 38, No. 151, pp. 387-404 https://doi.org/10.2307/2224316.
[14] Rubinshtein A. Ya. (2011) Guardian goods: institutional transformations// Voprosy ekonomiki. No 3 (in Russian)

[15] Rubinshtein A. Ya. (2018) Theory of guardian goods. Textbook. SPb, Aleteya (in Russian)

[16] Samuelson P. (1992) Economics. Moscow: NPO "Algon" VNIISI. 1992. Part 1 - 334 p., part 2 - 416 p. (in Russian)

[17] Schohl F. (1999) The paradoxical fate of the representative firm. Journal of the History of Economic Thought, Vol. 21, pp. 65-80. https://doi.org/10.1017/S1053837200002856.

[18] Smith A. An inquiry into the nature and causes of the wealth of nations. Moscow. 2016 (in Russian)

[19] Stiglitz J. E. (2002). Information and the change in the paradigm in economics. American Economic Review, Vol. 92, No. 3, pp. 460-501. https://doi.org/10/1257/00028280260136363.

[20] Tambovtsev V. L. Narrative analysis in economics as an ascent to complexity. Voprosy ekonomiki, No. 4, pp. 5-30 (in Russian)

[21] Tversky A., Kahneman D. (1971). Belief in the law of small numbers. Psychological Bulletin, Vol. 76, No. 2, pp. 105-110. https://doi.org/10.1037/h0031322.

[22] Williamson O. E. (1973). Markets and hierarchies. Some elementary considerations. American Economic Review, Vol. 63, No. 2, pp. 316-325. 